\title{
Modernization of Epi Surveillance in Kazakhstan: Transition to Risk Assessment and Real-Time Monitoring Based on Situational Center
}

\author{
Zhandarbek Bekshin ${ }^{2}$, Aizhan Esmagambetova², Stanislav Kazakov ${ }^{3}$, Alexry \\ Burdakov*1, Damir Kobzhasarov $^{2}$ and Andrey Ukharov ${ }^{1}$
}

'Black \& Veatch, Overland Park, KS, USA; ${ }^{2}$ Committee on Consumer Rights Protection of the Ministry of National Economics, Astana, Kazakhstan; ${ }^{3}$ Scientific-Practical Center of Sanitary-Epidemiological Expertise and Monitoring, Almaty, Kazakhstan

\section{Objective}

Development of a concept for sanitary-epidemiological monitoring system reinforcement in Kazakhstan based on the deployed electronic surveillance system, risk assessment and management approach, and establishment of a Situational Center.

\section{Introduction}

The sanitary-epidemiological monitoring system in Kazakhstan is passive and statistical in nature. Due to the modern threats, activation and emergence of new and recurring diseases (corona virus, Ebola, etc.) it is vital to transition from current epidemiological surveillance approaches to new prognostic, epi risk probability assessment, and bio risk management technologies, and in addition to urgent response develop preventive measures procedures to minimize the consequences of potential epi outbreaks.

\section{Methods}

A set of measures for epi surveillance system improvement and modernization was developed based on the following initiatives:

1) Implementation of a unified open-source Electronic Integrated Disease Surveillance System (EIDSS) (eidss.codeplex.com) in the epi surveillance and monitoring service [1]

2) Development of Regional Sanitary-Epidemiological Passports (RSEP) $[2,3]$

3) Creation of a republican Situational Center (SC)

The concept of SC creation is new for epidemiology in Kazakhstan. The SC will be a 24/7 working department with special staff collecting and aggregating epi information from all available internal and external sources.

The external threat assessment is based on the current situation in bordering territories, diseases in other countries that have international proliferation potential (confidential IHR 2005 site through the network of national WHO coordinators), and infectious diseases in other countries (ProMed, CDC networks and Ministry of Health websites).

The internal threat assessment is based on the currently used surveillance system Sanitary-Epidemiological Surveillance-1987, the implemented unified epi program EIDSS for 64 diseases, the developed RSEP, natural especially dangerous disease foci in Kazakhstan (available through maps and electronic geo-information systems), and the current state and capabilities of the national infection diagnostic laboratories.

\section{Results}

The following tasks will be executed based on the collected data:

1) Situational monitoring: information collection and analysis on the epi situation in real-time

2) Improvement and development of new risk prognosis methodology based on multi-factor analysis of internal and external sources [3]
3) Coordination of territorial units on emergency response: assessment of the situation regarding foci and in the country at large, readiness preparation monitoring of response units, coordination of services and units, and international cooperation

4) State authorities information brief (immediate access to emergency situations information, available through a website)

\section{Conclusions}

Active surveillance, risk assessment and prediction with a unified monitoring system within a Situational Center (SC) will improve epi situation control level. The SC will become the main source of reliable information on the epi situation in Kazakhstan as well as for trans-boundary epi risks to the republic. The SC can become the foundation for mutli-sectoral One Health collaboration on zoonotic diseases, as well the base element for regional cooperative systems within Global Health Security Agenda.

\section{Keywords}

risk assessment; real-time monitoring; situational center

\section{References}

1. Burdakov A. et al. Strengthening national One Health disease surveillance with open-source EIDSS // 16th International Congress on Infectious Diseases (ICID), Cape Town, South Africa, April 2-5, 2014.

2. Esmagambetova A. S., et al. Accuracy of eidss software prognosis on CCHF natural foci activity in Kazakhstan // International Society for Disease Surveillance (ISDS) 2013 Annual Conference, New Orleans, LA, USA.

3. Kazakov S.V. et.al. METHODOLOGY OF EPIDEMIC RISK MANAGEMENT AND PREVENTION IN NATURAL FOCI OF ESPECIALLY DANGEROUS PATHOGENS WITH OPENSOURCE EIDSS IN KAZAKHSTAN // IOHC 2015, Amsterdam, Netherlands, March 15-18, 2015.

*Alexry Burdakov

E-mail: burdakov@usa.net 